\title{
Transcriptome profiling of venom gland from wasp species: de novo assembly, functional annotation, and discovery of molecular markers
}

\author{
Junjie Tan ${ }^{1,2}$, Wenbo Wang ${ }^{2}$, Fan Wu' ${ }^{1}$ Yunming $\mathrm{Li}^{1}$ and Quanshui Fan ${ }^{2^{*}}$
}

\begin{abstract}
Background: Vespa velutina, one of the most aggressive and fearful wasps in China, can cause grievous allergies and toxic reactions, leading to organ failure and even death. However, there is little evidence on molecular data regarding wasps. Therefore, we aimed to provide an insight into the transcripts expressed in the venom gland of wasps.

Results: In our study, high-throughput RNA sequencing was performed using the venom glands of four wasp species. First, the mitochondrial cytochrome C oxidase submit I (COI) barcoding and the neighbor joining (NJ) tree were used to validate the unique identity and lineage of each individual species. After sequencing, a total of 127, 630 contigs were generated and 98,716 coding domain sequences (CDS) were predicted from the four species. The Gene ontology $(\mathrm{GO})$ enrichment analysis of unigenes revealed their functional role in important biological processes (BP), molecular functions (MF) and cellular components (CC). In addition, c-type, p1 type, p2 type and p3 type were the most commonly found simple sequence repeat (SSR) types in the four species of wasp transcriptome. There were differences in the distribution of SSRs and single nucleotide polymorphisms (SNPs) among the four wasp species.

Conclusions: The transcriptome data generated in this study will improve our understanding on bioactive proteins and venom-related genes in wasp venom gland and provide a basis for pests control and other applications. To our knowledge, this is the first study on the identification of large-scale genomic data and the discovery of microsatellite markers from $V$. tropica ducalis and $V$. analis fabricius.
\end{abstract}

Keywords: Venom gland, Wasps, Transcriptome, Simple sequence repeats, Single nucleotide polymorphisms

\section{Background}

Vespa velutina is native to Indochinese regions, Indonesia, and Taiwan [1, 2]. It was spread to France and Europe in 2004 [3] and was first recorded in South Korea in 2003 [4]. Vespa mandarinia smith is found in Korea, Japan, China, and Europe [5]. Vespa tropica

\footnotetext{
* Correspondence: qsfanquanshui@163.com; tan_somebody@163.com

${ }^{2}$ CDC of Western Theater Command, PLA, Chengdu 610021, China

Full list of author information is available at the end of the article
}

ducalis has been recorded in India, Japan, France, Nepal, and China [6]. Vespa analis Fabricius is mainly distributed in northern India, China, South Korea, Siberia, and Sumatra [7]. These wasps belong to the eusocial groups and live in dense bushlands or mountainous regions where they nest and prey on honeybees, insects, and even other wasps $[8,9]$. The wasps are the main carnivorous insects, which can effectively hunt and eliminate agricultural and forest pests such as Heliothis armigera,

(c) The Author(s). 2020 Open Access This article is licensed under a Creative Commons Attribution 4.0 International License, which permits use, sharing, adaptation, distribution and reproduction in any medium or format, as long as you give appropriate credit to the original author(s) and the source, provide a link to the Creative Commons licence, and indicate if changes were made. The images or other third party material in this article are included in the article's Creative Commons licence, unless indicated otherwise in a credit line to the material. If material is not included in the article's Creative Commons licence and your intended use is not permitted by statutory regulation or exceeds the permitted use, you will need to obtain permission directly from the copyright holder. To view a copy of this licence, visit http://creativecommons.org/licenses/by/4.0/ The Creative Commons Public Domain Dedication waiver (http://creativecommons.org/publicdomain/zero/1.0/) applies to the data made available in this article, unless otherwise stated in a credit line to the data. 
Artogeia rapae and locusts [10]. Their hunting habits can serve as an alternative efficient way for biological protection of some crops [11]. Therefore, the use of wasps to control pests can reduce pesticides-induced environmental pollution, with good economic and ecological benefits. However, due to their aggressiveness and activeness, wasps can also cause serious damage to farm industries, especially apiaries, and human health, particularly in allergic people, and can occasionally even be deadly [12]. Recent studies have shown that approximately 1300 people in New Zealand may seek medical services for wasp stings each year [13]. V. velutina, one of the most aggressive and fearful wasps in China, can cause grievous allergies and toxic reactions, leading to organ failure and even death [14]. The wasp sting can only be symptomatic and there is no specific treatment. Developing antivenin-like anti-bee venom has a good application prospect.

The commercial value of vespa amino acid mixtures (VAAM) is the economic significance of these species. VAAM has been shown to increase endurance during exercises such as swimming [15], decrease lactate accumulation and increase glucose concentration after running in mice [16]. VAAM ingestion has been shown to increase aerobic fitness and decrease intra-abdominal fat in women who exercise regularly [17]. However, wasp sting can cause skin hemorrhage and potentially lead to allergic reactions resulting in organ failure [18, 19]. Many bioactive peptides and macromolecular proteins, including enzymes, allergens, and toxins, are abundant in the venom of these wasps [20-22].

Currently, there are few studies on molecular data regarding wasps. Therefore, it is necessary to conduct more studies on gene sequences and regulation mechanisms to contribute to the in-depth understanding of their venom components and developing therapeutics for wasp stings. At present, the transcriptome of $V$. velutina has been deciphered, and related genes in the venom gland, such as the putative toxin sequences, have been revealed [14]. The mitochondrial genome sequence of $V$. mandarinia smith has been reported, and the phylogenetic analysis of this wasp was performed based on this information [23]. Moreover, the transcriptome profile of $V$. mandarinia smith was obtained using Illumina sequencing [5]. However, no genome or transcriptome information is as yet available for $V$. tropica ducalis and $V$. analis fabricius. Protein and peptide compounds are regarded as the bioactive substances in the wasp venom, and 398 wasp venom-related proteins were annotated in the UniProt database including mastoparan-like peptide, tachykinin-like peptide, vespin, melittin, venom protein and peptide, phospholipase, polybine, dominulin, and sodium channel subunit (https://www.uniprot.org/). These venom proteins can cause cell degranulation owing to the hemolytic activity [24] or via other relative physiological processes [22, 25, 26]. Despite this information, the genetic and molecular data are still limited and insufficient for high-throughput functional analysis to reveal the mechanisms associated with predation, breeding, communication, and other behaviors of these wasps. Furthermore, for exploring the toxicology of wasp injuries and pharmacology of wasp sting therapy, more information on the whole genome or transcriptome of these species is required to unravel rare gene regulators, new gene mutants, alternative splicing mechanisms, and microsatellite markers, which can promote further research on the target functional genes.

Wasp insects have many similarities in phenotype and morphology, which renders species-specific identification difficult. However, verification of the specific venom is significant for the clinical treatment of wasp injury. DNA barcoding is reported to be an efficient tool for species identification in both animals and plants [2729]. Snake venom was successfully separated using the mitochondrial $12 \mathrm{~S}$ gene [30] and the COI barcode [31]. This method was applied for the verification of spider and ant species [32-34]. Furthermore, DNA barcoding has also been reported for the identification and taxonomic classification of the wasp subfamily [35-37].

Whole DNA and RNA sequencing strategies have been successfully applied to address the genomic challenges in eusocial insects. In particular, transcriptome-wide studies have provided insights into caste systems, and the phenotypic plasticity of the genome has been studied in the facultatively eusocial bee, Megalopta genalis [38], Apis cerana cerana [39] and bumblebee, Bombus terrestris [40] by using conventional and high-throughput sequencing technologies. Next-generation sequencing (NGS) technology and the rapid development of highthroughput platforms have allowed the sequencing of non-model organisms.

In this study, we isolated RNA from the venom glands of four different species of Asian giant hornets, $V$. velutina, $V$. mandarinia smith, $V$. tropica ducalis, and $V$. analis fabricius and constructed a cDNA library for wholetranscriptome sequencing by using the latest Illumina platform HiSeq 4000. The sequencing raw reads were preprocessed to obtain quality reads and subsequently processed to obtain assembled contigs and unigene clusters using the Trinity de novo assembler. To our knowledge, this is the first study on the identification of large-scale genomic data and the discovery of microsatellite markers from $V$. tropica ducalis and $V$. analis fabricius.

\section{Results}

DNA barcoding and tree-based identification

After amplifying the COI gene-specific sequence of eight individuals from the four species, NJ-tree 
analysis based on the Kimura 2 Parameter distance (K2P) revealed the distinctive difference in COI sequences between the seven groups and estimated the intergeneric and intraspecific sequence divergences.

Based on COI sequence identification, the NJ tree revealed the unique lineage of these individuals, and the clustering information clarified the differences and similarities in the molecular sequences (Fig. 1 and Additional file 1). Seven different wasps were clearly distinguished. Notably, $V$. analis fabricius 1 and $V$. analis fabricius 7 were the factors that contribute to the group sequence variation of the other six unanimous individuals, indicating the occurrence of probable mutation or evolution process in this species ( $V$. analis fabricius). Therefore, DNA barcoding could possibly be applied for the identification of wasps with similar or unknown characteristics based on the COI sequence identification. The results also indicated that these species were distinct and could be used for subsequent comparison studies.

\section{RNA-Seq and de novo assembly of wasp transcriptome}

The cDNA libraries from the venom glands of 12 wasp individuals were sequenced using the Illumina platform. 452,427,244 clean and high-quality reads were obtained by deleting redundant transcripts, and the filtering rates of the sequencing reads ranged from 87.75 to $91.70 \%$ (Additional file 2). The clean and high-quality reads of RNA-Seq from the four wasp species were assembled into 127,629 contigs corresponding to $323,495,099$ base pairs (bp) in total (Table 1). The maximum contig length was 28 , $994 \mathrm{bp}$, and the minimum was $301 \mathrm{bp}$, with an average length of $2534 \mathrm{bp}$ and an N50 value of $3163 \mathrm{bp}$ (Table 1). In addition, the number of contigs differed across the four species, ranging from 65,229 to 76,458 , where the highest number was detected

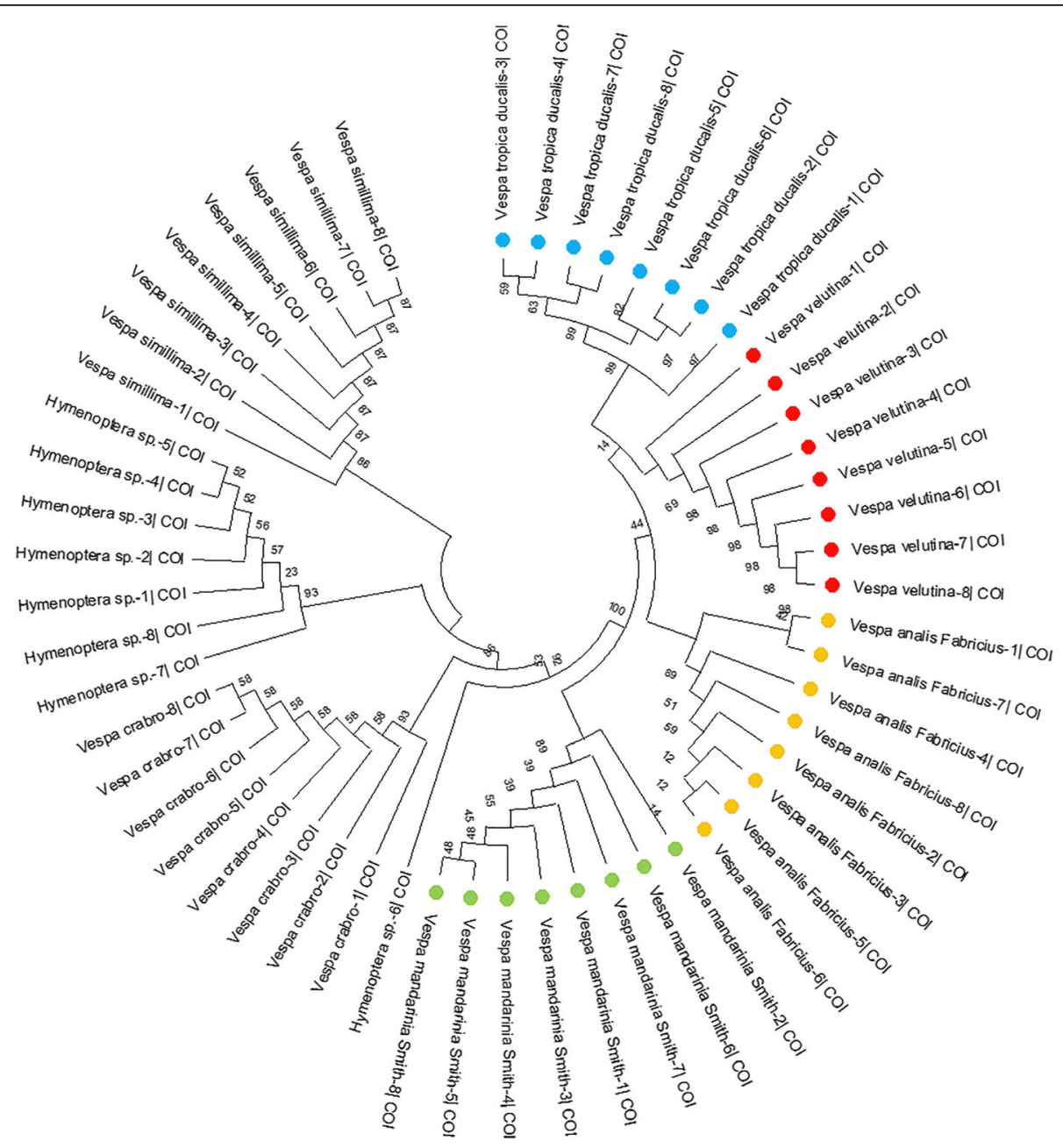

Fig. 1 Neighbor-joining tree of wasp samples based on COI gene. Orange color refers to $V$. velutina; green refers to $V$. analis fabricius; blue refers to $V$. tropica ducalis; red refers to $V$. mandarinia smith. Outgroup species: Vespa simillima simillima, Vespa crabro flavofasciata and Hymenoptera sp. 
Table 1 The statistics of the sequencing data after quality trimming

\begin{tabular}{|c|c|c|c|c|c|}
\hline \multirow[t]{2}{*}{ Item } & \multicolumn{4}{|l|}{ Samples } & \multirow[t]{2}{*}{ Total } \\
\hline & W & VAF & VTD & VMS & \\
\hline Number of contigs & 73,672 & 65,229 & 70,510 & 76,458 & 127,629 \\
\hline Number of characters (bp) & $90,906,977$ & $84,883,428$ & $84,763,580$ & $97,906,925$ & $323,495,099$ \\
\hline Average Length (bp) & 1234 & 1302 & 1202 & 1280 & 2534 \\
\hline Minimum Contigs Length & 301 & 301 & 301 & 301 & 800 \\
\hline Maximum Contigs Length & 27,683 & 27,018 & 24,129 & 28,994 & 36,048 \\
\hline N50 Length & 2026 & 2154 & 1957 & 2086 & 3163 \\
\hline Median Length & 694 & 728 & 677 & 726 & 1962 \\
\hline
\end{tabular}

Note: VV Vespa velutina group, VAF Vespa analis fabricius group, VTD Vespa tropica ducalis group, VMS Vespa mandarinia smith group

in $V$. mandarinia smith, possibly indicating more genome information (Table 1).

\section{Coding sequence domain prediction}

The open reading frame (ORF) and coding domain sequence (CDS) of the wasps were predicted using the sequence information and reference structures obtained from ORFfinder. In all, 3,557,399 CDSs were predicted and clustered, including different types of ORFs (Additional file 3).

\section{Homology-based annotation of transcripts}

The unigenes from the four different wasps were compared to the Flybase, KEGG, KOG, nr, Swiss-Prot, and Tox-Prot databases using BLASTX (E-value < $10^{-5}$ ), and the results showed that 374 unigenes were annotated in all of these databases (Fig. 2a). Furthermore, for individual wasp species, $V$. velutina, $V$. analis fabricius, $V$. tropica ducalis and $V$. mandarinia smith. $V$. mandarinia smith had 304, 316, 315 and 332 unigenes annotated into all databases, respectively

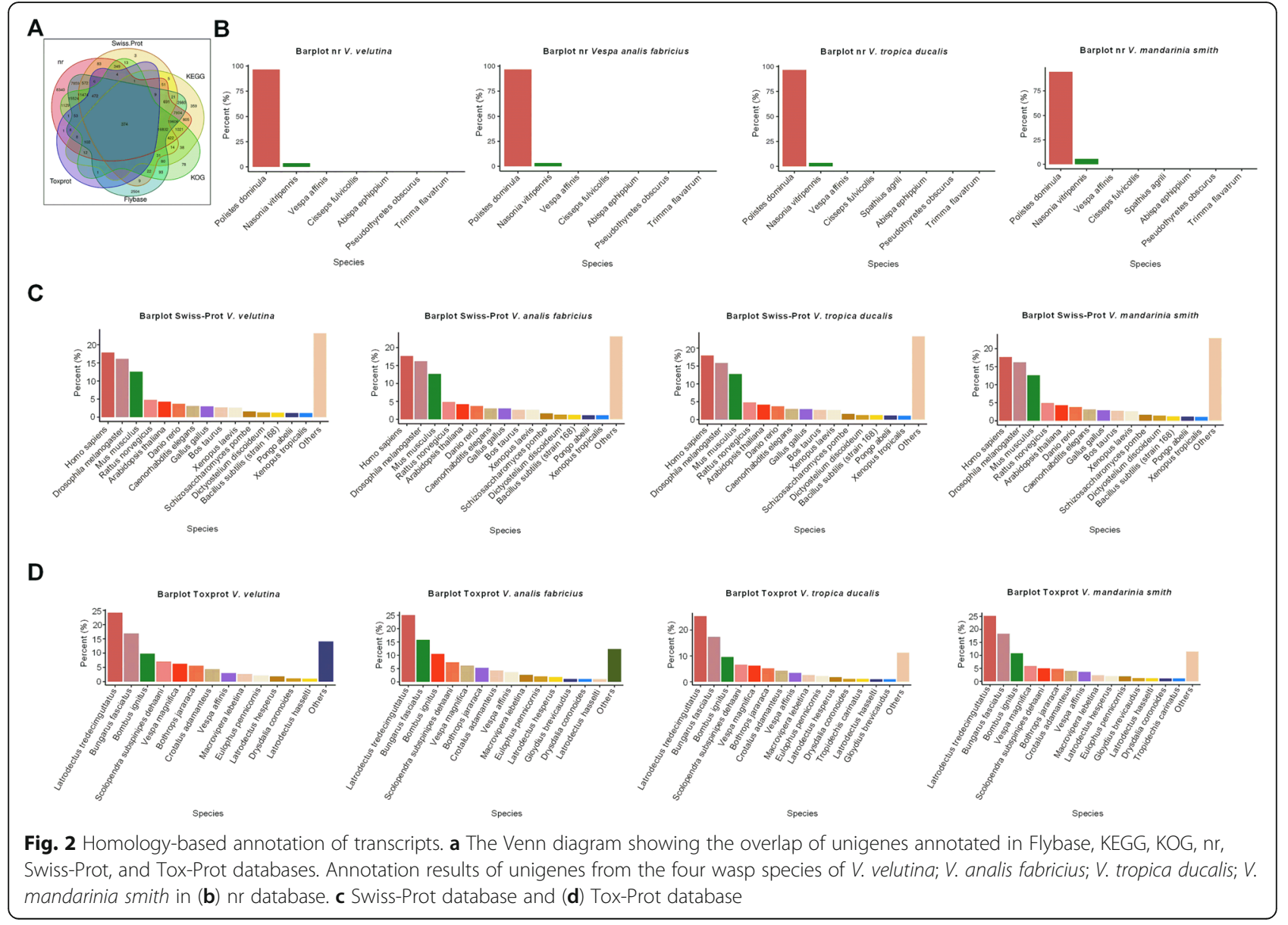


(Additional file 4). In the $\mathrm{nr}$ database, the species of the annotated homologous sequences of $V$. velutina, $V$. analis fabricius, $V$. tropica ducalis and $V$. mandarinia smith were mainly Polistes dominula (more than 90\%), Nasonia vitripennis and Vespa affinis (Fig. 2b). In the Swiss-Prot database, the species hits of the annotated homologous sequences of $V$. velutina, $V$. analis fabricius, $V$. tropica ducalis and $V$. mandarinia smith were mainly Homo sapiens, Drosophila melanogaster, Mus musculus and Rattus norvegicus (Fig. 2c). Moreover, in the Tox-Prot database, the species of the annotated homologous sequences of $V$. velutina, $V$. analis fabricius, $V$. tropica ducalis and $V$. mandarinia smith were mainly Latrodectus tredecimguttatus, Bungarus fasciatus, Bombus ignitus and Scolopendra subspinipes dehaani (Fig. 2d). These results indicated that the unigenes of the four different wasps $(V$. velutina, $V$. analis fabricius, $V$. tropica ducalis and $V$. mandarinia smith) were annotated in the nr, Swiss-
Prot and Tox-Prot database to obtain the similar species information.

We further plotted the classification of four species of wasp's venom toxins by using a blastx search for ToxProt database (Fig. 3). The results showed that $V$. velutina group and $V$. analis fabricius group had similar classification of toxins, mainly composed of Factor V activator RVV-V alpha, Scoloptoxin SSD076, Venom serine protease Bi-VSP, Probable phospholipase A1 magnifin and Thrombin-like enzyme flavoxobin (Fig. 3a, b). Venom serine protease Bi-VSP, Acetylcholinesterase, Scoloptoxin SSD976, Probable phospholipase A1 magnifin, and Alpha-latrocrustotoxin-Ltla (Fragment) accounted for a high proportion in the $V$. tropica ducalis group (Fig. 3c). In the V. mandarinia smith groups, the main annotated proteins were Acetylcholinesterase, Scoloptoxin SSD976, Factor V activator RVV-V alpha, Probable phospholipase A1 magnifin, and Venom serine protease Bi-VSP (Fig. 3d). These results indicated that

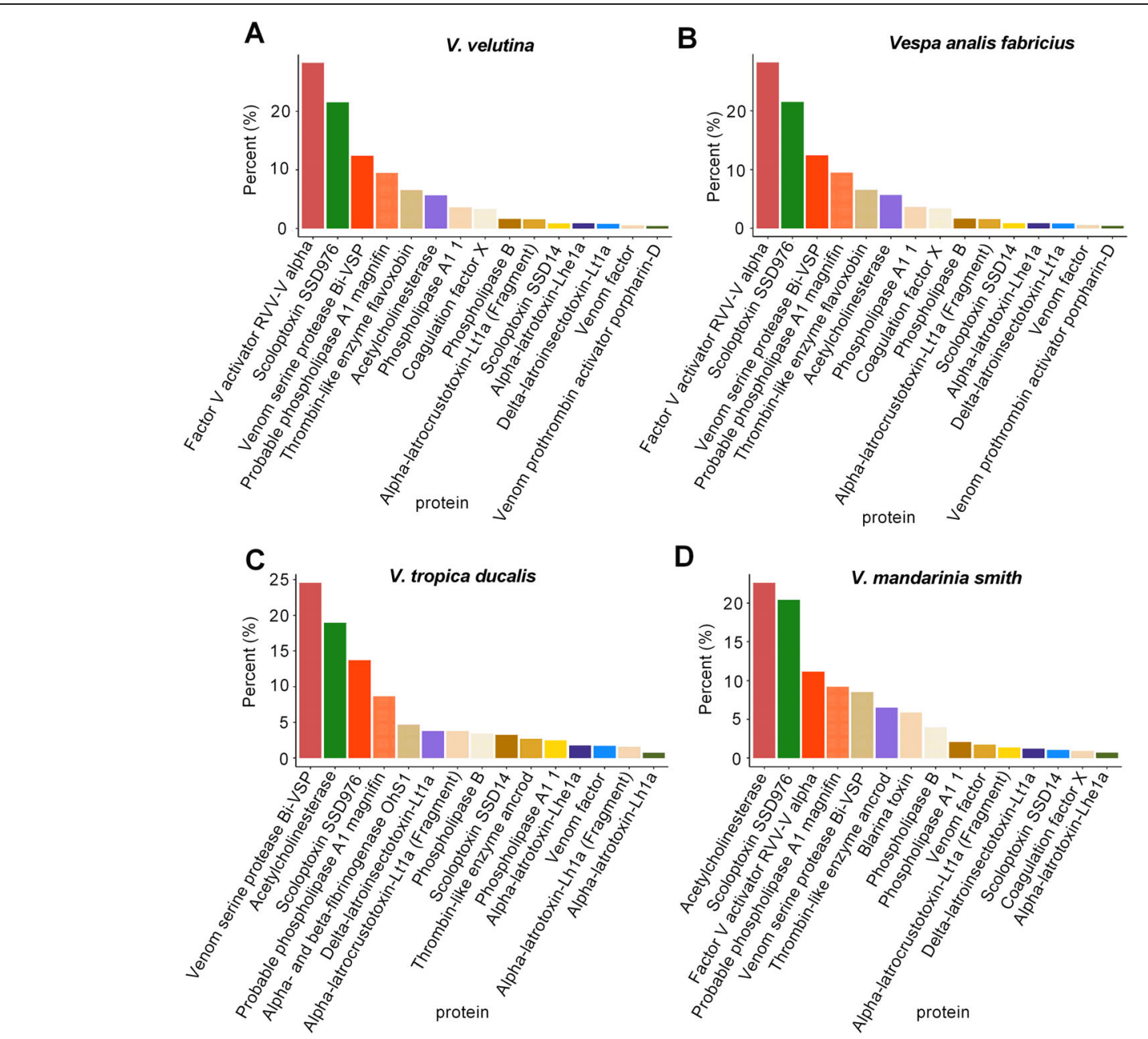

Fig. 3 Number of top hits with significant homologous to the toxins in Tox-Prot. a Top hits in Tox-Prot for Vespa velutina group. $\mathbf{b}$ Top hits in Tox-Prot for Vespa analis fabricius group. c Top hits in Tox-Prot for $V$. tropica ducalis group. $\mathbf{d}$ Top hits in Tox-Prot for $V$. mandarinia smith group 
the species and proportion of toxins contained in the four venom glands were different and may vary from species to species.

\section{GO enrichment analysis}

The GO enrichment of unigenes of $V$. velutina group showed that 136 terms were enriched and contained 69 terms in BP, 38 in MF, and 29 CC (Additional file 5). As shown in Fig. 4a, cilium organization and cilium assemble were significantly enriched in BP. Axoneme, ciliary part, ciliary plasm, plasma membrane bounded cell projection cytoplasm, centrosome and axoneme part were terms significantly enriched in $\mathrm{CC}$ while metallopeptidase activity, metalloendopeptidase activity, endopeptidase activity, Rho GTPase binding, and Rho guanylnucleotide exchange factor activity were significantly enriched in MF terms (Additional file 5).

The GO enrichment of unigenes of $V$. analis fabricius group showed that 136 terms composed of 74 terms in $\mathrm{BP}, 36$ in MF, and 26 in CC were enriched (Additional file 6). As shown in Fig. 4b, cilium organization and cilium assemble were significantly enriched in BP; ciliary part, axoneme, ciliary plasm, and plasma membrane bounded cell projection cytoplasm were significantly enriched in CC; and metallopeptidase activity, metalloendopeptidase activity, Rho GTPase binding, and Rho guanyl-nucleotide exchange factor activity were significantly enriched in MF (Additional file 6).

The GO enrichment of unigenes of $V$. tropica ducalis group showed that 136 terms were classified as BP (70 terms), MF (39 terms), and CC (17 terms) (Additional file 7). As shown in Fig. 4c, cilium organization and cilium assemble were significantly enriched in BP; axoneme, ciliary part, ciliary plasm, and plasma membrane bounded cell projection cytoplasm were significant enriched in CC; and metallopeptidase activity and metalloendopeptidase activity were significant enriched in MF (Additional file 7).

The GO enrichment of unigenes of $V$. mandarinia smith group showed that 166 terms were enriched and could be classified as BP ( 88 terms), MF (43 terms), and CC (35 terms) (Additional file 8). As shown in Fig. 4d,

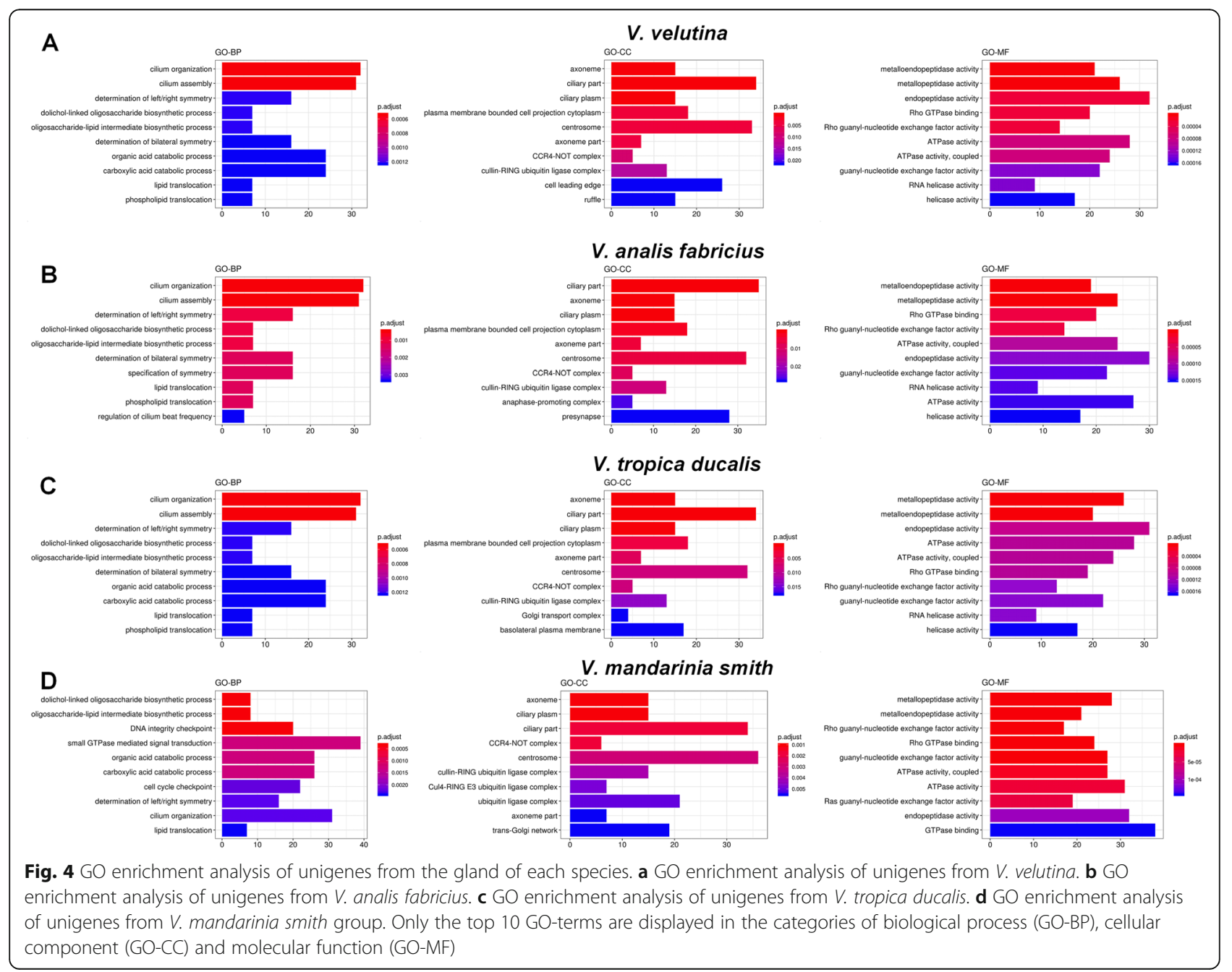


dolichol-linked oligosaccharide biosynthetic process, oligosaccharide-lipid intermediate biosynthetic process, and DNA integrity checkpoint were significantly enriched in BP. Axoneme, ciliary plasm, ciliary part and CCR4-NOT complex were significantly enriched in CC while metallopeptidase activity, metalloendopeptidase activity, Rho guanyl-nucleotide exchange factor activity, Rho GTPase binding, guanyl-nucleotide exchange factor activity, ATPase activity, coupled, and ATPase activity were significantly enriched in MF (Additional file 8).

Through the Venn diagram we found that 1608 unigenes were common to the four species of wasp ( $V$. velutina, $V$. analis fabricius, $V$. tropica ducalis and $V$. mandarinia smith) (Fig. 5a). Additionally, as shown in Fig. 5a, the specific unigenes detected in $V$. velutina, $V$. analis fabricius, $V$. tropica ducalis and V. mandarinia smith were 990, 981, 297 and 5141, respectively (Fig. 5a). Among them, V. mandarinia smith had the most unique unigenes, indicating that $V$. mandarinia smith may have more genomic information than the other three species of wasps.

We further carried out GO enrichment analysis on the shared and specific unigenes of the four species of wasp.
The GO enrichment of unigenes shared by the four species of wasp showed that 1089 GO terms (904 in BP, 74 in MF, and 111 CC) could be enriched (Additional file 9). As shown in Fig. 5b, epithelial cell differentiation, epithelial cell development, wing disc development, ovarian follicle cell development and columnar/cuboidal epithelial cell development were terms significantly enriched in BP; apical part of cell, cell junction, neuron projection, and cell cortex were terms significantly enriched in CC; heme binding, tetrapyrrole binding, cofactor binding and iron ion binding were significantly enriched in MF (Additional file 9).

GO enrichment analysis of unigenes specific to each of the four wasp species showed that only $V$. velutina and $V$. mandarinia smith groups had enrichment data. The GO enrichment of unigenes specific to $V$. velutina showed that 45 GO terms were enriched and included 33 terms in BP, 8 in MF, and 4 in CC (Additional file 10). As shown in Fig. 5c, negative regulation of gene silencing by RNA, regulation of neuronal synaptic plasticity, regulation of gene silencing by miRNA, regulation of posttranscriptional gene silencing, and production of
A

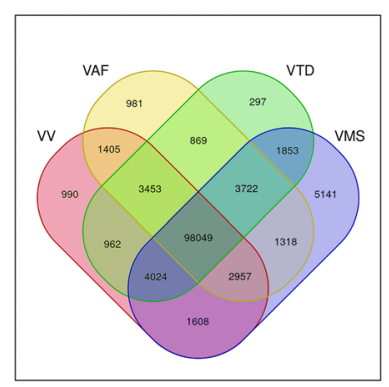

C

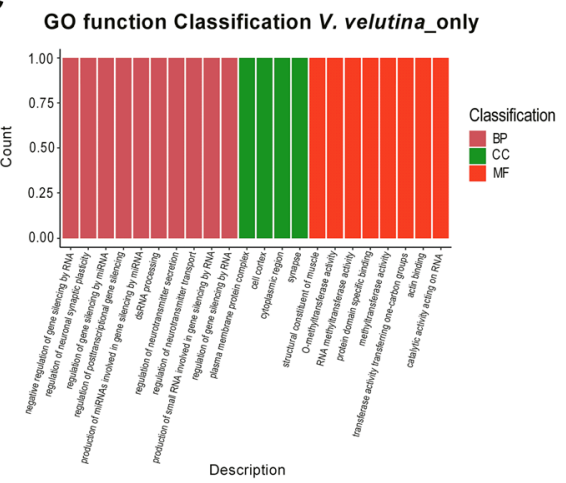

GO function Classification shared

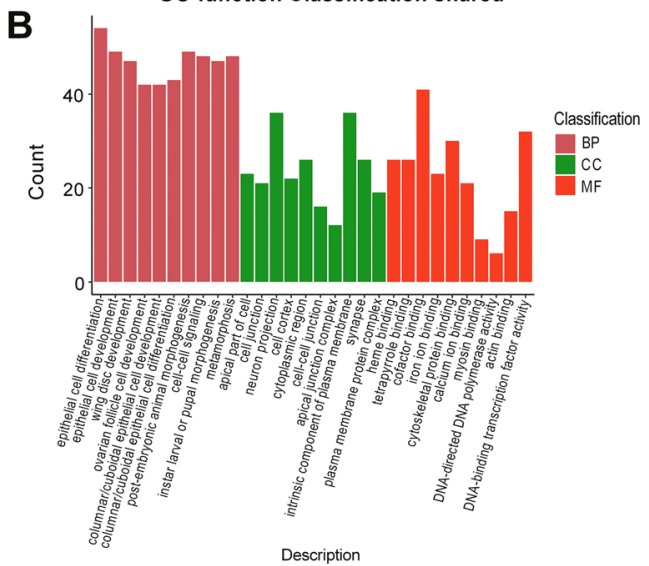

D

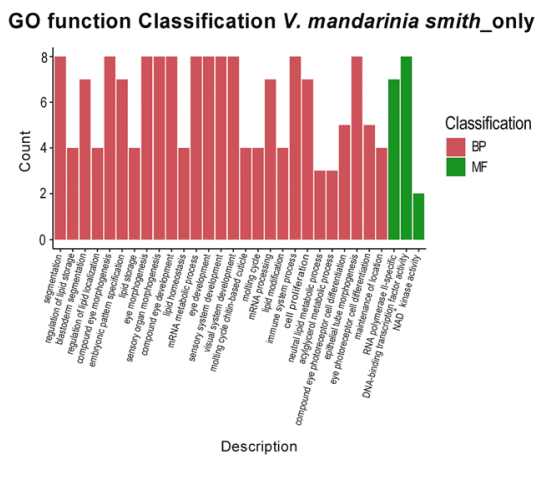

Fig. $5 \mathrm{GO}$ enrichment analysis of common and specific unigenes of the four wasp species. a The Venn diagram showing that the common and specific unigenes of $V$. velutina (V), $V$. analis fabricius (VAF), $V$. tropica ducalis (VTD) and $V$. mandarinia smith (VMS). $\mathbf{b}$ GO enrichment analysis of unigenes shared by the four wasp species. c GO enrichment analysis of unigenes specific to $V$. velutina. $\mathbf{d} \mathrm{GO}$ enrichment analysis of unigenes specific to $V$. mandarinia smith 
miRNAs involved in gene silencing by miRNA were significantly enriched in BP while plasma membrane protein complex, cell cortex, cytoplasmic region, and synapse were terms significantly enriched in CC. Terms such as structural constituent of muscle, Omethyltransferase activity, RNA methyltransferase activity and protein domain specific binding were those significantly enriched in MF (Additional file 10).

The GO enrichment of unigenes specific to $V$. mandarinia smith showed that 30 terms (27 in BP and 3 in MF) were enriched (Additional file 11). As shown in Fig. $5 \mathrm{~d}$, segmentation, regulation of lipid storage, blastoderm segmentation, regulation of lipid localization, and compound eye morphogenesis were significant enriched in BP; RNA polymerase II-specific, DNA-binding transcription factor activity, and $\mathrm{NAD}^{+}$kinase activity were significantly enriched in MF (Additional file 11).

\section{SSR and SNP analysis}

SSR analysis was performed on the four species of wasp transcriptome samples using the MIcroSAtellite identification tool (MISA) software. The results showed that 195, 330, 193,994, 195,152 and 196,691 SSRs were detected in the $V$. velutina, $V$. analis fabricius, $V$. tropica ducalis and $V$. mandarinia smith transcriptome samples, respectively, for a total of 8 SSR types, namely c, c*, p1, p2, p3, p4, p5 and p6 (Fig. 6a). Among them, c-type, p1 type, p2 type and $\mathrm{p} 3$ type were the most commonly found SSR types in the transcriptome of the four wasp species.

SNP variants were analyzed separately according to the species, and these mutations could result in synonymous, nonsynonymous and even some frame-shift in transcription process. The results showed that 269,585 (198,185 for transition and 71,400 for transversion), 254, 863 (184,699 for transition and 70,164 for transversion), 266,084 (190,664 for transition and 75,420 for transversion) and 253,901 (187,321 for transition and 66,580 for transversion) SNPs were identified in the $V$. velutina, $V$. analis fabricius, $V$. tropica ducalis and $V$. mandarinia smith transcriptomes, respectively. As shown in Fig. 6b, the number of transition types $(\mathrm{C}->\mathrm{T}, \mathrm{A}->\mathrm{G}, \mathrm{G}->\mathrm{A}$ and $\mathrm{T}->\mathrm{C})$ was significantly higher than the transversion types (A-> T, G- > T, T- > A, C- > G, A- > G, C->A, $\mathrm{T}->\mathrm{G}$ and $\mathrm{G}->\mathrm{C}$ ), where $\mathrm{C}->\mathrm{T}$ type was the most abundant of all four species of wasp samples. There were differences in the distribution of SNPs among the four species of wasp, and $V$. tropica ducalis had a higher C$>\mathrm{T}$ type whereas $V$. velutina had a higher T->C type.

\section{Discussion}

With the development of NGS technology and bioinformatics methods, RNA sequencing, unlike traditional

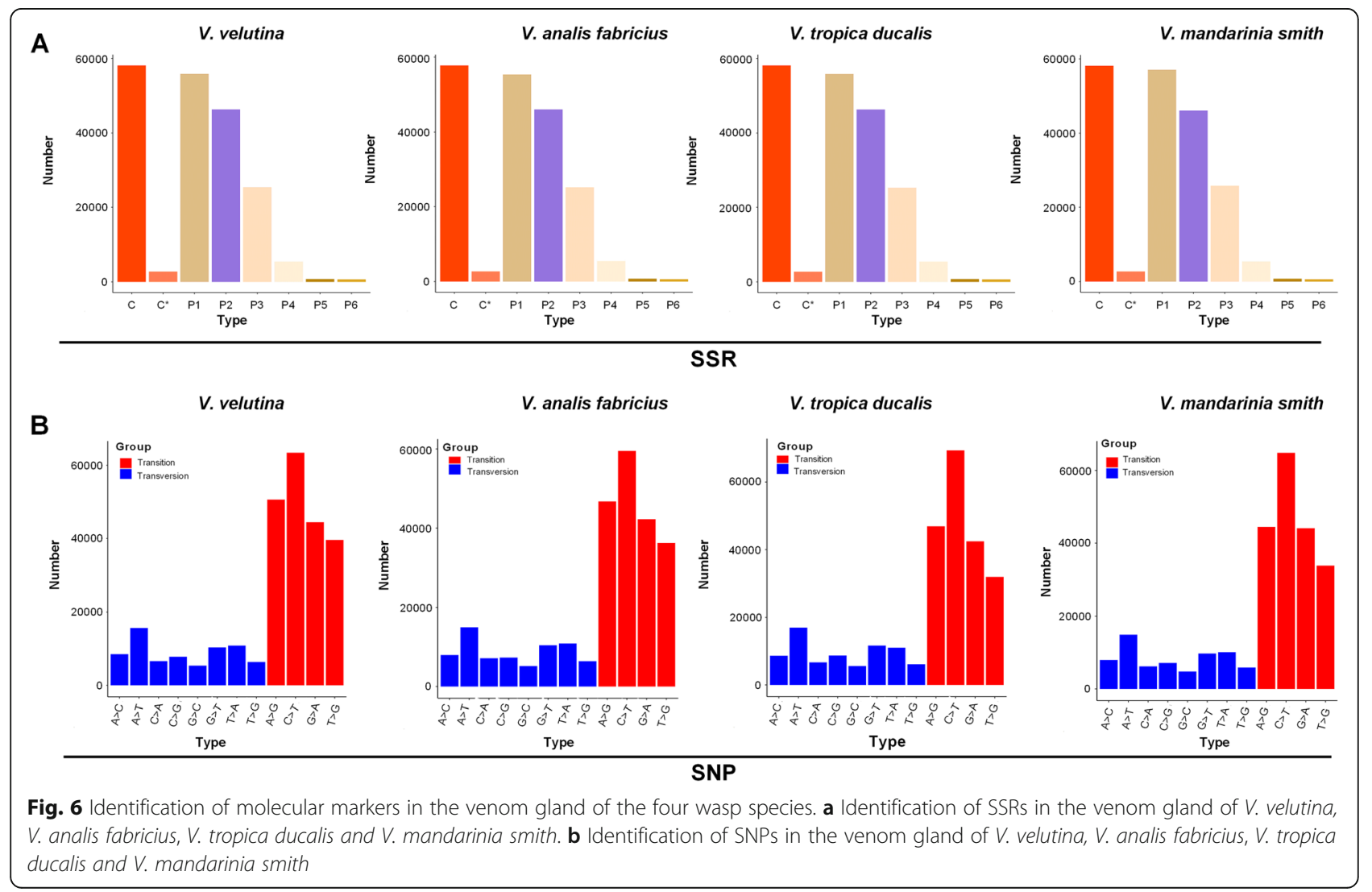


Sanger sequencing, can yield high-throughput and highquality transcriptome data, which has been introduced as a vital tool for scientific researches [41-44]. To the best of our knowledge, this is the first study to develop a full-scale map of $V$. tropica ducalis, $V$. analis fabricius, and the specific wasp subfamily $V$. mandarinia smith. More details and information on $V$. velutina were also obtained. The transcriptome of the venom glands of the four wasp species were analyzed using the Illumina Hiseq4000 RNA-seq platform. The assembled contigs were annotated and blasted into the published database of fruit fly, which revealed 98,716 CDSs, of which 67,076 annotated genes and 24,539 unannotated genes were aligned. Unannotated unigenes probably belong to untranslated regions, non-coding RNA, novel genes and short sequences without protein domains or assembly errors, and suggest that the wasp venom likely has some uncharacterized sequences. We further found that 1608 unigenes were detected in all four species of wasp ( $V$. velutina, $V$. analis fabricius, $V$. tropica ducalis and $V$. mandarinia smith). The specific unigenes detected in $V$. velutina, $V$. analis fabricius, $V$. tropica ducalis and $V$. mandarinia smith were 990, 981, 297 and 5141, respectively. Among them, $V$. mandarinia smith had the higher number of specific contigs, indicating that $V$. mandarinia smith may have more genomic information than the other three species of wasps. Thus, our study might directly or indirectly promote or contribute to the completion of the sequencing of wasp venom.

The unigenes of the four wasp species were searched for the Tox-Prot database by blastx to annotate the venom protein. We found that these unigenes were annotated as Factor $\mathrm{V}$ activator RVV-V alpha, Acetylcholinesterase, Venom serine protease Bi-VSP, Scoloptoxin SSD076, Probable phospholipase A1 magnifin, Thrombin-like enzyme flavoxobin, etc. Studies have shown that factor $\mathrm{V}$ activator and thrombin-like enzyme are involved in the blood coagulation cascade, which has been reported in the $V$. velutina venom gland, but rarely reported in other Hymenoptera insects [14]. The role of bee venom serine protease is reported only in Bombus ignitus as a prophenoloxidase activating factor, triggering a cascade of phenoloxidase, which acts like a snake venom serine protease and has fibrin (ogen) olytic activity [45, 46]. Previous studies showed that phospholipase A1 magnifin, identified from the Vespa affinis venom gland, is involved in serum IgE responses as a major allergenic protein [47]. Acetylcholinesterase has been found in the venom of $V$. velutina, which plays key roles in neurotransmission through inactivating the acetylcholine, ultimately resulting in paralysis of the prey $[14,48]$. These data provide clinical support for the potential use of venom gland proteins and is expected to be used for developing specific anti-bee venom similar to anti-venom serum.

Due to the influence of factors such as individual differences, sex differences and geographical environment differences, it is easy to confuse similar species in the traditional identification of wasps. DNA barcoding approach was found to be an efficient method for classifying wasp species. The mitochondrial COI gene has the characteristics of high evolution rate, obvious interspecific variation and relatively conservative species, and has been widely used as an effective DNA barcoding for species classification and evolution analysis $[49,50]$. The success rate of DNA barcoding method was nearly $100 \%$, as verified by the RNA-Seq process. Similar barcoding procedures have been used in snakes [31], spiders [51], and parasitoid wasps [52], showing the feasibility and efficiency of this method in distinguishing specific DNA sequences in the venom. In this study, based on COI sequence identification, the NJ tree indicated that the $V$. analis fabricius -1 and-7 COI sequences were divergent from the other six COI sequences. They were homologous and all clustered in the same big branch, indicating that they were from the same subspecies, the $V$. analis fabricius -1 and -7 COI might have undergone different changes under environmental and evolutionary pressures. It also revealed the unique lineage of these individuals, and the clustering information clarified the differences and similarities in the molecular sequences.

The traditional development method of SSR molecular markers is to construct DNA libraries for screening, which is costly and inefficient, and the application of high-throughput sequencing technology brings down to large-scale screening of SSR molecular markers [53]. SSR is a significant molecular marker for specific functional gene studies, genetic linkage map construction, as well as evolutionary analysis of plants and animals [54, 55]. In this study, 8 types of SSR were detected in the four wasp species, of which c, p1, p2 and p3 were the most common SSR types in the four species of wasp. Moreover, SNP molecular marker technology is the third generation of molecular marker technology after SSR. It can fully reflect the genetic and variational levels of the population by studying its distribution in the biological genome. In molecular evolution, it is common for nucleotide transitions to be several times higher than transversions. In Stoltzfus' et al. study, they integrated eight studies about the fitness for replacement mutations and found that transitions were more suitable than transversions at a $53 \%$ chance (95\% CI 50 to 56 ). It confirmed that the transitions conservative 
evolutionary frequency of crossings was increased [56]. In this study, we found that the number of transition types was significantly higher than the types of transversion, and the distribution of SNPs among the four species of wasp was also different. These data are valuable for further molecular researches of the wasps. Furthermore, the valuable genetic information (SSRs and SNPs) might be useful for research on functional genes by using genomic and proteomic tools, and can be developed to help conserve wasp species in their preferred habitat. In this study, we found that a number of genes were shared by the four species while other genes were specific to each wasp species. In addition, most of the genes could not be annotated in the databases. These observations indicated that there is a large number of genes in the venom gland of wasp species that need to be identified. Identifying these genes will further our understanding on the toxins produced by these species. This will play a significant role in the applications of wasp species to pest control and medical purposes. Until then, the annotated genes discovered in the present study will be useful for current studies but the validation of these genes by additional molecular biology techniques and functional analysis by experimentation will be performed in our future studies.

\section{Conclusions}

In this study, the complete transcriptome of four wasps ( $V$. velutina, $V$. mandarinia smith, $V$. analis fabricius, and $V$. tropica ducalis) was sequenced using the Illumina HiSeq 4000 NGS platform. The sequences were assembled into meaningful unigene sequences by using the de novo assembler Trinity and the clustering tool TGICL. The unigene sequences were annotated into publicly available protein sequence databases for putative functional attributes, especially their assignment to GO categories. This information provides clinical support for the potential use of venom gland proteins and is expected to be used for developing specific antibee venom similar to anti-venom serum. In addition, we obtained a set of reliable SSR and SNP markers from the unigene sequences. This valuable genetic information should be useful for studying functional genes by using genomic and proteomic tools.

\section{Methods}

\section{Insects}

Four social wasp species with different phenotypes were collected from wild populations in Baoshan (Yunnan province, China). All wasps were collected directly from the nests by using forceps, preserved immediately in RNAlater (Ambion, Invitrogen, Applied Biosystems) and stored at $-20^{\circ} \mathrm{C}$ until analysis. At the very beginning, wasps were classified according to their morphological differences. Wasps with yellow feet were classified into the $V$. velutina group. Wasps with a golden ring were classified into the $V$. mandarinia smith group. Wasps with a black rump were classified into the $V$. tropica ducalis group while wasps with thick skin were classified into the $V$. analis fabricius group. The "Wildlife Protection Law of the People's Republic of China" stipulates that:

- Article 2: The wildlife protected by this Law refers to the precious and endangered terrestrial and aquatic wildlife and terrestrial wildlife with important ecological, scientific and social values.

- Article 21: It is forbidden to hunt, kill or kill wildlife under special state protection.

After investigation, we found that wasp species are not included in the "National List of Key Wildlife Protection", and in fact, there is a large number of wasps species, which are ubiquitous and are not endangered species, so they are not considered as "wild animals" protected by the "Wild Animal Protection Law". Therefore, no ethical approval nor permission was required for collecting and carrying out experiments on the four wasp species ( $V$. velutina, $V$. tropica ducalis, $V$. analis fabricius and $V$. mandarinia smith), which are neither endangered nor protected species.

\section{DNA barcoding}

Proteinase $\mathrm{K}$ was used to digest the preserved tissues followed by addition with phenol-chloroform to extract the total genomic DNA. The concentration was determined using a UV spectrophotometer. DNA samples were diluted with concentrations ranging from 30.0 to $80.0 \mathrm{ng} / \mu \mathrm{l}$ for the next step. Subsequently, based on previous studies [57], the mitochondrial cytochrome $\mathrm{C}$ oxidase submit I (COI) gene was amplified using the universal primers HC02198 and LC01490 in a reaction volume of $25 \mu$ l containing $2.5 \mu \mathrm{l}$ of $10 \times$ PCR buffer, $1.5 \mu \mathrm{l}$ of $10 \mu \mathrm{M}$ primer, $2 \mu \mathrm{l}$ of dNTP, $0.25 \mu \mathrm{l}$ of Taq polymerase, $2 \mu \mathrm{l}$ of genomic DNA, and $16.75 \mu \mathrm{l}$ of PCR water. The PCR cycling profiles were as follows: $5 \mathrm{~min}$ initial denaturation at $94{ }^{\circ} \mathrm{C}$, followed by 5 cycles of pre-amplification for 30 $\mathrm{s}$ at $94{ }^{\circ} \mathrm{C}$, annealing for $30 \mathrm{~s}$ at $50{ }^{\circ} \mathrm{C}$ to $45^{\circ} \mathrm{C}$, and extension for $30 \mathrm{~s}$ at $72{ }^{\circ} \mathrm{C}$. Next, 35 cycles of amplification were run at $94{ }^{\circ} \mathrm{C}$ for $30 \mathrm{~s}, 45^{\circ} \mathrm{C}$ for $30 \mathrm{~s}$, and $72{ }^{\circ} \mathrm{C}$ for $30 \mathrm{~s}$, and a final extension for $10 \mathrm{~min}$ at 
$72{ }^{\circ} \mathrm{C}$. The PCR products were extracted and purified. Subsequently, sequencing was performed by Sanger sequencing.

The nucleotide sequences were aligned in MEGA 6.0 [58] with default parameters, which pairwise and multiple alignment with the gap opening penalty was both 10 and the gap extension penalty was 0.1 and 0.2 , respectively. The formulation of $C R=\Sigma[\sigma \mathrm{i} /$ $\mu \mathrm{i}] 2 /(\mathrm{n}-3)$, where $\mathrm{n}$ is the number of sequences, was used to generate a $95 \%$ confidence interval. BLAST search was performed by inputting the FASTA file in the nucleotide database in GenBank (https://blast. ncbi.nlm.nih.gov/Blast.cgi). Then we obtained the gene sequence with high homology and download it to FASTA format. Moreover, we used CLUSTAL X to perform multiple sequence alignment to generate a guide tree file (DND file). Finally, based on the DND file that generated by CLUSTAL $X$, a neighbor-joining tree (NJ-tree) was generated using MEGA 6.0, and the intergenic, interspecific, and intraspecific sequence distances were estimated. All of the insertions and deletions were tested by the bootstrap method with 1000 replicates, and the nucleotide sequences with homologies of $100 \%$ were isolated as representative to construct the phylogenetic tree.

\section{RNA extraction, library construction, and sequencing}

Total RNAs were isolated from the venom gland tissues by using RNeasy Micro Kit (Qiagen, France) according to the manufacturer's instructions. Sequencing and cDNA library preparation were performed using Beckman Coulter Genomics services (http://www.beckmangenomics.com/). The mRNA extracted from the venom gland tissues was reverse transcribed into cDNA and amplified using the Ovation RNA-Seq System V2 kit (NuGEN Technologies Inc., USA). After cDNA fragmentation, end-repair and purification were performed using the Agencourt AMPure XP kit (Agencourt Bioscience, Beckman Coulter, San Carlos, CA, USA), and TruSeq sequencing adapters (Illumina, USA) were ligated to cDNA fragments. Finally, the library was PCR-amplified (14 cycles) to about $30 \mathrm{ng} / \mu \mathrm{l}$ by using a high-fidelity DNA polymerase (Beckman Genomics, USA). Illumina TruSeq adapters were ligated to the $5^{\prime}$ and $3^{\prime}$ ends of the cDNA of both samples. The cDNA was finally amplified by PCR using a proofreading enzyme (Beckman Genomics, USA). For Illumina sequencing, the cDNA samples were fractionated on agarose gels ranging in the size from 300 to $500 \mathrm{bp}$. PCR amplification was designed for TruSeq sequencing using the HiSeq4000 technology according to the instructions of Illumina.

\section{Sequence filtering, de novo assembly, and assembly validation}

The raw sequencing data was assessed using FASTQC (http://www.bioinformatics.babraham.ac.uk/projects/fastqc/), including quality distribution of nucleotides, position-specific sequencing quality, GC content, PCR duplication proportion, and kmer frequency. The quality score was set over 30 to obtain an accuracy of $99.9 \%$. The filtered reads for each sample were merged and de novo assembled using Trinity software [43]. The operating parameters of Trinity program were: $\mathrm{k}$-mer $=25$, the minimum $\mathrm{k}$ mer coverage $=2$, the maximum length expected between the pair of fragments $=500$, the minimum overlap with the reading of the transcript $\mathrm{PE}=75$ and the maximum number of readings anchored in a single figure $=200,000$ [59]. After that, three software modules (Inchworm, Chrysalis, and Butterfly) were applied using Trinity and the joint sequences were clustered using Cap3 [60]. CAP3 used base quality for constructing the alignment of reads and generating a consistent sequence for each Contig. The distance recognized by CAP3 and the inserted value generally differ by 1000 to $1500 \mathrm{bp}$, and the default quality value of each base is 10 [60]. The fastq type reads and paired reads were assembled into contigs, generating a final reference sequence, which was used for functional annotation analysis.

\section{Transcriptome annotation and analysis}

Unigene annotation was conducted using a series of bioinformatics approaches. The published databases, including NCBI non-redundant protein (nr) databases (http://www.ncbi.nlm.nih.gov/), the Gene ontology database (http://www.geneo ntology.org/), the KEGG database (http://www.genome.jp/kegg/), the Swiss-Prot database (http://www.uniprot.org/keywords/), and the Tox-Prot database (http://www.uniprot.org/program/Toxins) were used to search for unigene annotations and sequence alignments. Certain algorithms were performed using BLASTX (parameter values showed in Tables 2 and 3) with the E-value cutoff of $1 \mathrm{E}-5$ for pathway assignment, domain/family comparison, and mapping. The molecular function (MF), biological process (BP), including GO annotation and classification, and cellular component (CC) ontologies were conducted using Blast2GO program. Furthermore, the unigenes were equally mapped to the Flybase, KEGG, KOG, Swiss-Prot, and Tox-Prot (animal toxin database) except $\mathrm{nr}$ databases for the prediction and 
Table $\mathbf{2}$ The parameters list for blastx software running in diverse databases

\begin{tabular}{ll}
\hline Item & $\begin{array}{l}\text { Parameter value (Flybase, KEGG, KOG, Swiss-Prot, and } \\
\text { Tox-Prot databases) }\end{array}$ \\
\hline Query & UniGene.fa \\
Db & index/uniprot_sprot.fasta \\
Out & swiss_prot_result.blast-its-1.xl \\
Evalue & 1 e-5 \\
Max_target__ & 1 \\
seqs & \\
outfmt & "6 qseqid ssegid salltitles qlen qstart qend slen sstart \\
& send evalue bitscore pident staxids qcovs" \\
num_threads & 40
\end{tabular}

classification of potential functions by using the BWA-MEM algorithm of BWA software. The nr database with huge data and selected by limiting the BLAST + search by taxonomy (-taxidlist wasplst.txt) to reduce the scope of search efficiency and calculation time.

\section{GO enrichment analysis}

$\mathrm{GO}$ analysis was applied to analyze the main function of unigenes according to Gene Ontology [61]. We computed the $P$-values for the GOs of all unigenes. Within the significant category, the relative enrichment was given as follows: $\operatorname{Re}=\left(\mathrm{n}_{\mathrm{f}} / \mathrm{n}\right) /\left(\mathrm{N}_{\mathrm{f}} / \mathrm{N}\right)$, where $\mathrm{n}_{\mathrm{f}}$ is the number of unigenes in a particular category, $\mathrm{n}$ is the total number of genes in the same category, $\mathrm{N}_{\mathrm{f}}$ is the number of unigenes in the entire array, and $\mathrm{N}$ is the total number of genes in the array.

\section{Genomic analysis for putative molecular markers}

More information on the genome was obtained by performing Single Sequence Repeat (SSR) and Single Nucleotide Polymorphisms (SNP) analyses. The MIcroSAtellite identification tool, a script from perl

Table 3 The parameters list for blastx software running in $\mathrm{nr}$ database

\begin{tabular}{ll}
\hline Item & $\begin{array}{l}\text { Parameter value } \\
\text { (nr database) }\end{array}$ \\
\hline Query & 4.UniGene.fa \\
Db & /home/tmp_database/nr_v5/nr_v5 \\
taxidlist & wasplst.txt \\
Out & nr_result.blast-its--1.xl \\
Evalue & 1 e-5 \\
Max_target_ & 1 \\
seqs & \\
outfmt & "6 qsegid sseqid salltitles qlen qstart qend slen sstart \\
num_threads & 40 \\
\hline
\end{tabular}

for identifying SSRs, was applied for detecting one to six bases of repeat units. The density and distribution of different SSR types were determined in the whole genome. Primer 3 (http://primer3.sourceforge.net/) was run under default parameters to design SSR primers. Moreover, GATK software was used to align the exon reads and reference sequence and SNPs were picked [62]. For information about GATK's best practices for SNP calls, please see the GATK's official website (http://www.broadinstitute.org/gatk/guide/ best-practices).

\section{Supplementary information}

Supplementary information accompanies this paper at https://doi.org/10. 1186/s12864-020-06851-0.

Additional file 1. The results of homologous alignment of seven vespa groups.

Additional file 2. The statistics of the sequencing data of 12 wasp individuals.

Additional file 3. Results of ORF prediction using ORFfinder.

Additional file $\mathbf{4}$ Venn diagram showing the intersection of anaotation results from blast against Flybase, KEGG, KOG, nr, Swiss-Prot and Tox-Prot database. (A) The intersection of the significant hits for $V$. velutina. (B) The intersection of the significant hits for $V$. analis fabricius. (C) The intersection of the significant hits for $V$. tropica ducalis (D) The intersection of the significant hits for $V$. mandarinia smith.

Additional file $\mathbf{5}$ The $\mathrm{GO}$ enrichment of unigenes from venom gland of $V$. velutina.

Additional file $\mathbf{6}$ The $\mathrm{GO}$ enrichment of unigenes from venom gland of $V$. analis fabricius.

Additional file $\mathbf{7}$ The $\mathrm{GO}$ enrichment of unigenes from venom gland of V. tropica ducalis.

Additional file 8 The $\mathrm{GO}$ enrichment of unigenes from venom gland of V. mandarinia smith.

Additional file 9. The GO enrichment of unigenes shared by the venom gland of the four wasp species.

Additional file $\mathbf{1 0}$ The $\mathrm{GO}$ enrichment of unigenes specific to the venom gland of $V$. velutina.

Additional file $\mathbf{1 1}$ The $\mathrm{GO}$ enrichment of unigenes specific to the venom gland of $V$. mandarinia smith.

\section{Abbreviations}

COI: Cytochrome C oxidase submit I; NGS: Next-generation sequencing; SNP: Single Nucleotide Polymorphisms; VAAM: Vespa amino acid mixtures

\section{Acknowledgements}

None.

\section{Authors' contributions}

$J T$ participated in the design of the study, sample collection, experimental work, data analysis, interpretation of the results and manuscript editing. WW, $\mathrm{YL}$ and FW carried out the experimental work and contributing to the writing of the manuscript. QF contributed to study design and supervised the whole research. All authors read and approved the final version of the manuscript.

\section{Funding}

This study was supported by the China Postdoctoral Science Foundation (2017M623429). 


\section{Availability of data and materials}

All data generated or analyzed during this study are included in this published article and its supplemental files. Twelve transcriptome sequencing data for four species of wasp have been uploaded to the NCBI Sequence Read Archive (SRA, http://www.ncbi.nlm.nih.gov/Traces/sra) database under the accession numbers: SRR9157365-SRR9157376.

\section{Ethics approval and consent to participate}

The "Wildlife Protection Law of the People's Republic of China" stipulates that:

- Article 2: The wildlife protected by this Law refers to the precious and endangered terrestrial and aquatic wild life and terrestrial wildlife with important ecological, scientific and social values.

- Article 21: It is forbidden to hunt, kill or kill wildlife under special state protection.

After investigation, we found that wasp species are not included in the "National List of Key Wildlife Protection", and in fact, there is a large number of wasps species, which are ubiquitous and are not endangered species, so they are not considered as "wild animals" protected by the "Wild Animal Protection Law". Therefore, no ethical approval nor permission was required for collecting and carrying out experiments on the four wasp species $(V$. velutina, $V$. tropica ducalis, V. analis fabricius and V. mandarinia smith), which are neither endangered nor protected species.

\section{Consent for publication}

Not applicable.

\section{Competing interests}

The authors declare that they have no competing interests.

\section{Author details}

${ }^{1}$ General Hospital of Western Theater Command, Chengdu 610021, China. ${ }^{2}$ CDC of Western Theater Command, PLA, Chengdu 610021, China.

\section{Received: 18 December 2019 Accepted: 18 June 2020}

\section{Published online: 24 June 2020}

\section{References}

1. Archer ME. Taxonomy, distribution and nesting biology of species of the genus Dolichovespula (Hymenoptera, Vespidae). J Entomol Sci. 2006;9(3): 281-93.

2. Gawas SM, Kumar PG, Gupta A, Sureshan PM. Checklist of vespid wasps (Hymenoptera: Vespidae) of Goa, India, with new records and a key to species. Zootaxa. 2019:4585(2):zootaxa.4585.4582.4583.

3. Monceau K, Thiery D. Vespa velutina nest distribution at a local scale: an 8year survey of the invasive honeybee predator. Insect Sci. 2017;24(4):663-74

4. Choi MB, Martin SJ, Lee JW. Distribution, spread and impact of the invasive hornet Vespa velutina in South Korea. Entomol Res. 2012:15(3):473-7.

5. Patnaik BB, Park SY, Kang SW, Hwang HJ, Wang TH, Park EB, Chung JM, Song DK, Kim C, Kim S. Transcriptome profile of the Asian giant hornet (Vespa mandarinia) using illumina HiSeq 4000 sequencing: de novo assembly, functional annotation, and discovery of SSR markers. Int J Genomics. 2016;2016(4):4169587.

6. Dong D. A preliminary study on the biology of wasps vespa velutina auraria smith and vespa tropica ducalis smith (Hymenoptera:Vespidae). Zool Res. 1989;10(2):155-62.

7. Bequaert J. The oriental Vespa Analis Fabricius and its color forms, with a note on the synonymy of Vespa esakii Sonan and Vespa formosana Sonan (Hymenoptera: Vespidae). Trans Am Entomol Soc. 1939:65(1):37-42.

8. Taylor BJ, Nordheim EV, Schueller TI, Jeanne RL. Recruitment in swarmfounding wasps: polybia occidentalis does not actively scent-mark carbohydrate food sources. Psyche. 2011;2011:7.

9. Choi MB, Kwon O. Occurrence of Hymenoptera (wasps and bees) and their foraging in the southwestern part of Jirisan National Park, South Korea. J Ecol Environ. 2015;38(3):367-74

10. Saleh M, El-Wakeil N, Elbehery H, Gaafar N, Fahim S. Biological pest control for sustainable agriculture in Egypt. In: The handbook of environmental chemistry, vol. 77. Cham: Springer; 2017.

11. Rose EAF, Harris RJ, Glare TR. Possible pathogens of social wasps (Hymenoptera: Vespidae) and their potential as biological control agents. N Z J Zool. 1999;26(3):179-90.
12. Monceau $\mathrm{K}$, Bonnard $\mathrm{O}$, Thiéry $\mathrm{D}$. Vespa velutina : a new invasive predator of honeybees in Europe. J Pest Sci. 2014;87(1):1-16.

13. Ward D. Status of control options for Vespula wasps in New Zealand. Auckland: Landcare Research; 2013.

14. Liu Z, Chen S, Zhou Y, Xie C, Zhu B, Zhu H, Liu S, Wang W, Chen H, Ji Y. Deciphering the venomic transcriptome of killer-wasp Vespa velutina. Sci Rep. 2015;5:9454.

15. Abe T, Takiguchi Y, Tamura M, Shimura J, Yamazaki K-I. Effects of Vespa amino acid mixture (VAAM) Isolated from hornet larval saliva and modified VAAM nutrients on endurance exercise in swimming mice. Tairyoku Kagaku. 1995:44(2):225-37.

16. Tsuchita H, Shirai-Morishita Y, Shimizu T, Abe T. Effects of a Vespa amino acid mixture identical to hornet larval saliva on the blood biochemical indices of running rats. Nutr Res. 1997;17(6):999-1012.

17. Sasai H, Matsuo T, Fujita M, Saito M, Tanaka K. Effects of regular exercise combined with ingestion of vespa amino acid mixture on aerobic fitness and cardiovascular disease risk factors in sedentary older women: a preliminary study. Geriatr Gerontol Int. 2011;11(1):24-31.

18. Erdmann SM, Sachs B, Kwiecien R, Moll-Slodowy S, Sauer I, Merk HF. The basophil activation test in wasp venom allergy: sensitivity, specificity and monitoring specific immunotherapy. Allergy. 2015:59(10):1102-9.

19. Yanagawa Y, Morita K, Sugiura T, Okada Y. Cutaneous hemorrhage or necrosis findings after Vespa mandarinia (wasp) stings may predict the occurrence of multiple organ injury: a case report and review of literature. Clin Toxicol. 2007:45(7):803.

20. Higashijima T, Uzu S, Nakajima T, Ross EM. Mastoparan, a peptide toxin from wasp venom, mimics receptors by activating GTP-binding regulatory proteins (G proteins). J Biol Chem. 1988;263(14):6491-4.

21. Souza BM, Mendes MA, Santos LD, Marques MR, Cesar LM, Almeida RN, Pagnocca FC, Konno K, Palma MS. Structural and functional characterization of two novel peptide toxins isolated from the venom of the social wasp Polybia Paulista. Peptides. 2005;26(11):2157-64.

22. Ombati R, Wang Y, Du C, Lu X, Li B, Nyachieo A, Li Y, Yang S, Lai R. A membrane disrupting toxin from wasp venom underlies the molecular mechanism of tissue damage. Toxicon. 2018;148:56-63.

23. Chen PY, Wei SJ, Liu JX. The mitochondrial genome of the Vespa mandarinia Smith (Hymenoptera: Vespidae: Vespinae) and a phylogenetic analysis of the Vespoidea. Mitochondrial DNA A DNA Mapp Seq Anal. 2016; 27(6):4414-5.

24. de Souza BM, Marques MR, Tomazela DM, Eberlin MN, Mendes MA, Palma MS. Mass spectrometric characterization of two novel inflammatory peptides from the venom of the social wasp Polybia Paulista. Rapid Commun Mass Spectrom. 2010;18(10):1095-102.

25. Ribeiro SP, Mendes MA, Dos Santos LD, de Souza BM, Marques MR, de Azevedo WF Jr, Palma MS. Structural and functional characterization of Nterminally blocked peptides isolated from the venom of the social wasp Polybia Paulista. Peptides. 2004;25(12):2069-78.

26. Gilchrist J, Das S, Van Petegem F, Bosmans F. Crystallographic insights into sodium-channel modulation by the beta4 subunit. Proc Natl Acad Sci U S A 2013;110(51):E5016-24

27. Evans N, Paulay G. DNA barcoding methods for invertebrates. Methods Mol Biol. 2012;858:47-77.

28. Weigt LA, Driskell AC, Ormos A, Meyer C, Collins A. Introduction to animal DNA barcoding protocols. Methods Mol Biol. 2012;858:11-6.

29. Wilson JJ. DNA barcodes for insects. Methods Mol Biol. 2012;858:17-46.

30. Pook CE, Mcewing R. Mitochondrial DNA sequences from dried snake venom: a DNA barcoding approach to the identification of venom samples. Toxicon. 2005;46(7):711-5.

31. Supikamolseni A, Ngaoburanawit N, Sumontha M, Chanhome L, Suntrarachun S, Peyachoknagul S, Srikulnath K. Molecular barcoding of venomous snakes and species-specific multiplex PCR assay to identify snake groups for which antivenom is available in Thailand. Genet Mol Res. 2015; 14(4):13981-97.

32. Ng'endo RN, Osiemo ZB, Brandl R. DNA barcodes for species identification in the hyperdiverse ant genus Pheidole (Formicidae: Myrmicinae). J Insect Sci. 2013;13:27.

33. Gaikwad S, Warudkar A, Shouche Y. Efficacy of DNA barcoding for the species identification of spiders from Western Ghats of India. Mitochondrial DNA A DNA Mapp Seq Anal. 2017;28(5):638-44.

34. Wang $Z L$, Yang $X Q$, Wang TZ, Yu X. Assessing the effectiveness of mitochondrial COI and $16 \mathrm{~S}$ rRNA genes for DNA barcoding of farmland 
spiders in China. Mitochondrial DNA A DNA Mapp Seq Anal. 2018;29(5):695702.

35. Zaldivar-Riveron A, Martinez JJ, Ceccarelli FS, De Jesus-Bonilla VS, RodriguezPerez AC, Resendiz-Flores A, Smith MA. DNA barcoding a highly diverse group of parasitoid wasps (Braconidae: Doryctinae) from a Mexican nature reserve. Mitochondrial DNA. 2010;21(Suppl 1):18-23.

36. Yoon TJ, Kim JK. Taxonomy of Eumenes punctatus-complex (Hymenoptera: Vespidae: Eumeninae) from Korea with DNA barcoding and key to far eastern species of the genus Eumenes Latreille, 1802. Zootaxa. 2014;3893(2): 232-42.

37. Gutierrez-Arellano D, Gutierrez-Arellano CR, Zaldivar-Riveron A. DNA barcoding of the parasitoid wasp subfamily Doryctinae (Hymenoptera: Braconidae) from Chamela, Mexico. Biodivers Data J. 2015;(3):e5109.

38. Jones BM, Wcislo WT, Robinson GE. Developmental transcriptome for a facultatively Eusocial Bee, Megalopta genalis. G3 (Bethesda). 2015;5(10):212735. Published 2015 Aug 14. https://doi.org/10.1534/g3.115.021261. PMID: 26276382. PMCID: PMC4592995.

39. Zhao H, Peng Z, Du Y, Xu K, Guo L, Yang S, Ma W, Jiang Y. Comparative antennal transcriptome of Apis cerana cerana from four developmental stages. Gene. 2018;660:102.

40. Li L, Su S, Perry CJ, Elphick MR, Chittka L, Sã Vik E. Large-scale transcriptome changes in the process of long-term visual memory formation in the bumblebee, Bombus terrestris. Sci Rep. 2018;8(1):534.

41. Birol I, Jackman SD, Nielsen CB, Qian JQ, Varhol R, Stazyk G, Morin RD, Zhao Y, Hirst M, Schein JE, et al. De novo transcriptome assembly with ABySS. Bioinformatics. 2009;25(21):2872-7.

42. Trapnell C, Williams BA, Pertea G, Mortazavi A, Kwan G, van Baren MJ, Salzberg SL, Wold BJ, Pachter L. Transcript assembly and quantification by RNA-Seq reveals unannotated transcripts and isoform switching during cell differentiation. Nat Biotechnol. 2010;28(5):511-5.

43. Grabherr MG, Haas BJ, Yassour M, Levin JZ, Thompson DA, Amit I, Adiconis X, Fan L, Raychowdhury R, Zeng Q, et al. Full-length transcriptome assembly from RNA-Seq data without a reference genome. Nat Biotechnol. 2011;29(7): 644-52.

44. Chang Z, Li G, Liu J, Zhang Y, Ashby C, Liu D, Cramer CL, Huang X. Bridger: a new framework for de novo transcriptome assembly using RNA-seq data. Genome Biol. 2015;16:30.

45. Cerenius L, Söderhäll K. The prophenoloxidase-activating system in invertebrates. Immunol Rev. 2004;198(1):116-26.

46. Swenson S, Markland F Jr. Snake venom fibrin (ogen) olytic enzymes. Toxicon. 2005;45(8):1021-39.

47. Sookrung N, Wong-Din-Dam S, Tungtrongchitr A, Reamtong O, Indrawattana N, Sakolvaree Y, Visitsunthorn N, Manuyakorn W, Chaicumpa W. Proteome and allergenome of Asian wasp, Vespa affinis, venom and lgE reactivity of the venom components. J Proteome Res. 2014;13(3):1336-44.

48. Frobert Y, Creminon C, Cousin X, Remy MH, Chatel JM, Bon S, Bon C, Grassi J. Acetylcholinesterases from Elapidae snake venoms: biochemical, immunological and enzymatic characterization. Biochim Biophys Acta. 1997; 1339(2):253-67.

49. Feng Y, Li Q, Kong L, Zheng X. DNA barcoding and phylogenetic analysis of Pectinidae (Mollusca: Bivalvia) based on mitochondrial COI and 165 rRNA genes. Mol Biol Rep. 2011;38(1):291-9.

50. Cheng J, Sha Z-L, Liu R-Y. DNA barcoding of genus Metapenaeopsis (Decapoda: Penaeidae) and molecular phylogeny inferred from mitochondrial and nuclear DNA sequences. Biochem Syst Ecol. 2015; 61(2015):376-84

51. Binford GJ, Callahan MS, Bodner MR, Rynerson MR, Núñez PB, Ellison CE, Duncan RP. Phylogenetic relationships of Loxosceles and Sicarius spiders are consistent with Western Gondwanan vicariance. Mol Phylogenet Evol. 2008; 49(2):538-53.

52. Jenkins C, Chapman TA, Micallef JL, Reynolds OL. Molecular techniques for the detection and differentiation of host and parasitoid species and the implications for fruit fly management. Insects. 2012;3(3):763-88.

53. Guo R, Wang S, Xue R, Cao G, Hu X, Huang M, Zhang Y, Lu Y, Zhu L, Chen $F$. The gene expression profile of resistant and susceptible Bombyx mori strains reveals cypovirus-associated variations in host gene transcript levels. Appl Microbiol Biotechnol. 2015;99(12):5175-87.

54. Li YC, Korol AB, Fahima T, Nevo E. Microsatellites within genes: structure, function, and evolution. Mol Biol Evol. 2004:21(6):991-1007.
55. Kashi Y, King DG. Simple sequence repeats as advantageous mutators in evolution. Trends Genet. 2006;22(5):253-9.

56. Stoltzfus A, Norris RW. On the causes of evolutionary transition: transversion bias. Mol Biol Evol. 2016:33(3):595-602.

57. Vrijenhoek R. DNA primers for amplification of mitochondrial cytochrome c oxidase subunit I from diverse metazoan invertebrates. Mol Mar Biol Biotechnol. 1994;3(5):294-9.

58. Tamura K, Stecher G, Peterson D, Filipski A, Kumar S. MEGA6: molecular evolutionary genetics analysis version 6.0. Mol Biol Evol. 2013;30(12):2725-9.

59. Zhu H, Wang H, Zhu Y, Zou J, Zhao FJ, Huang CF. Genome-wide transcriptomic and phylogenetic analyses reveal distinct aluminumtolerance mechanisms in the aluminum-accumulating species buckwheat (Fagopyrum tataricum). BMC Plant Biol. 2015;15:16.

60. Huang X, Madan A. CAP3: a DNA sequence assembly program. Genome Res. 1999:9(9):868-77.

61. Consortium GO. Gene ontology consortium: going forward. Nucleic Acids Res. 2015;43(Database issue):D1049-56.

62. Zhu P, He L, Li Y, Huang W, Xi F, Lin L, Zhi Q, Zhang W, Tang YT, Geng C, et al. OTG-snpcaller: an optimized pipeline based on TMAP and GATK for SNP calling from ion torrent data. PLoS One. 2014;9(5):e97507.

\section{Publisher's Note}

Springer Nature remains neutral with regard to jurisdictional claims in published maps and institutional affiliations.

\section{Ready to submit your research? Choose BMC and benefit from:}

- fast, convenient online submission

- thorough peer review by experienced researchers in your field

- rapid publication on acceptance

- support for research data, including large and complex data types

- gold Open Access which fosters wider collaboration and increased citations

- maximum visibility for your research: over $100 \mathrm{M}$ website views per year

At BMC, research is always in progress.

Learn more biomedcentral.com/submissions 